\title{
Application of flow field-flow fractionation for the characterization of macromolecules of biological interest: a review
}

\author{
Rashid Nazir Qureshi • Wim T. Kok
}

Received: 15 July 2010 /Revised: 14 September 2010 /Accepted: 19 September 2010 /Published online: 20 October 2010

(C) The Author(s) 2010. This article is published with open access at Springerlink.com

\begin{abstract}
An overview is given of the recent literature on (bio) analytical applications of flow field-flow fractionation (FIFFF). FIFFF is a liquid-phase separation technique that can separate macromolecules and particles according to size. The technique is increasingly used on a routine basis in a variety of application fields. In food analysis, FIFFF is applied to determine the molecular size distribution of starches and modified celluloses, or to study protein aggregation during food processing. In industrial analysis, it is applied for the characterization of polysaccharides that are used as thickeners and dispersing agents. In pharmaceutical and biomedical laboratories, FIFFF is used to monitor the refolding of recombinant proteins, to detect aggregates of antibodies, or to determine the size distribution of drug carrier particles. In environmental studies, FIFFF is used to characterize natural colloids in water streams, and especially to study trace metal distributions over colloidal particles. In this review, first a short discussion of the state of the art in instrumentation is given. Developments in the coupling of FIFFF to various detection modes are then highlighted. Finally, application studies are discussed and ordered according to the type of (bio) macromolecules or bioparticles that are fractionated.
\end{abstract}

Keywords Flow field-flow fractionation .

Biomacromolecules · Bioparticles $\cdot$ Molecular weight distribution $\cdot$ Particle size distribution

Published in the special issue Separation Science of Macromolecules with Guest Editor André Striegel

\footnotetext{
R. N. Qureshi • W. T. Kok $(\bowtie)$

Analytical Chemistry Group,

van 't Hoff Institute for Molecular Sciences,

University of Amsterdam,

PO Box 94157, 1090 GD Amsterdam, The Netherlands

e-mail: W.Th.Kok@uva.nl

R. N. Qureshi

e-mail: R.N.Qureshi@uva.nl
}

\section{Introduction}

The simple, soft, and fast separation mechanism of flow field-flow fractionation (FlFFF) has made it a valuable technique when size-based separations of macromolecules, molecular aggregates, colloids, or solid particles are required. Although after the first experimental study on FlFFF by Giddings et al. [1], over 40 years ago, the development and application of the technique was largely limited to a small number of research laboratories, it is now becoming competitive with other separation techniques. This is at least partly related to the fact that robust and reliable systems have been made available by different manufacturers. Now, FIFFF systems are used on a routine basis in industrial, pharmaceutical, environmental, and clinical laboratories. Recently, detailed reviews have been published on various applications of field-flow fractionation in general, e.g., $[2,3]$.

In this review the emphasis is on analytical applications of FlFFF for the separation and characterization of macromolecules and particles of biological origin. The scientific literature from 2005 up to mid 2010 is covered. After a short description of the state of the art in instrumentation, applications to various macromolecular compound types and to bioparticles and colloids will be discussed.

\section{Instrumentation}

In most laboratories where FlFFF is applied, an asymmetrical FlFFF (AsFlFFF) system is used. The AsFlFFF separation channel has only one wall which is permeable for the carrier liquid; the cross flow, that is the underlying force for the separation, is created as a part of the in-going flow. AsFlFFF instruments are less complex than the 
original symmetrical systems (with two permeable walls and a separate cross-flow delivery). The separation performances of asymmetrical and symmetrical systems are comparable. For the optimization of AsFlFFF separations, a special approach is required [4]. In the choice of the channel dimensions and the flow rates applied a compromise has to be found between separation power and the detectability (dilution) of the sample compounds to be separated.

Standard AsFlFFF channels have a volume of the order of 1-2 $\mathrm{mL}$, and flow rates of the order of $1-5 \mathrm{~mL} / \mathrm{min}$ are used. In bioanalytical applications, in cases when only small samples are available, sample dilution may be too strong with such a standard channel. Therefore, miniaturization of FlFFF has been studied by several groups. Yohannes et al. [5] have shown that a relatively simple downscaling of the channel volume, by a factor of approximately 10 , is possible without loss of performance. Permeable hollow fibers have been studied as separation channels by Reschiglian et al. [6, 7], by the group of Moon [8-10], and in our laboratory [11]. With hollow fibers the volume scale of the separation can be downscaled and the instrumental complexity reduced, and possibilities are foreseen to develop "disposable" separation channels for, e.g., clinical use. So far, however, hollow-fiber FlFFF (HFFlFFF) systems have not been made commercially available.
Reschiglian et al. [6] coupled an HFFlFFF system through an electrospray interface to a (time-of-flight) mass spectrometer. The HFFIFFF-electrospray ionization (ESI)time-of-flight mass spectrometry (MS) system could be used for the separation and identification of intact proteins. The carrier liquid could be optimized with respect to its compatibility with ESI-MS. An additional benefit of the coupling of the HFFIFFF system to the mass spectrometer was the desalting of the sample that occurred during the separation. When an ammonium acetate solution was used as the carrier liquid, no multiple sodium adducts were formed in the ESI, and the resulting mass spectra were considerably simplified (see Fig. 1). In AsFlFFF systems, detection can be performed with standard concentration detectors as used in liquid chromatography (LC), such as refractive index (RI), UV absorbance, or fluorescence detectors.

The FIFFF techniques separate according to the hydrodynamic volume of the sample compounds. For additional information on the size and shape of the separated compounds, online light scattering techniques can be used. Static light scattering detection, usually in the multiangle light scattering (MALS) variant, is often used in a variety of application fields. With MALS the molecular weight of macromolecules and the radius of gyration of macro-
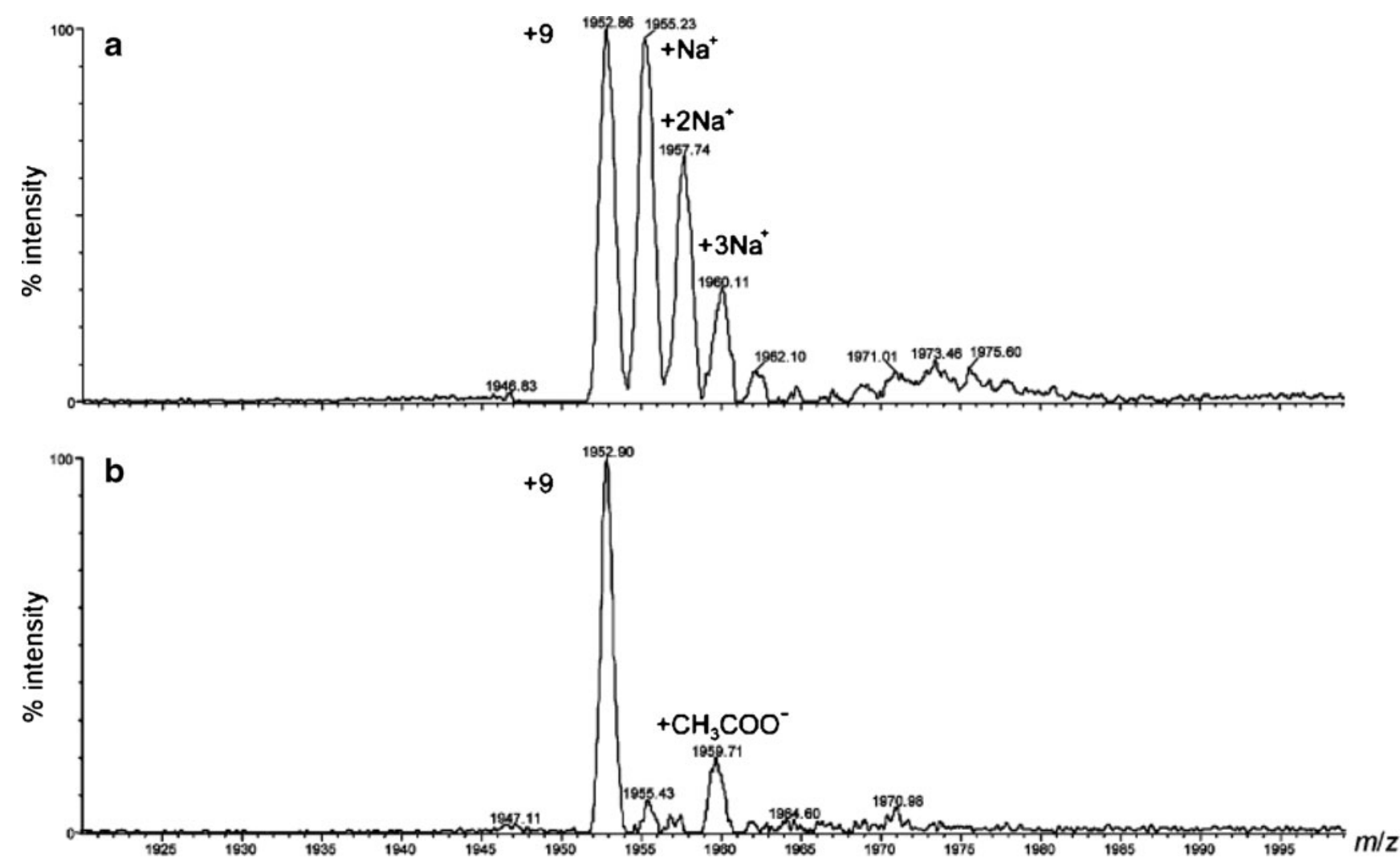

Fig. 1 Time-of-flight mass spectra of myoglobin, with direct infusion (a) and after hollow-fiber field-flow fractionation (HFFlFFF) separation (b). (Reproduced from [6], with permission) 
molecules and particles can be obtained. A new development is online coupling of FlFFF with dynamic light scattering (DLS), or quasi-elastic light scattering (QELS), a combination that is now commercially available. With online DLS the hydrodynamic size or the diffusion coefficient of the separated species can be estimated directly $[12,13]$.

An interesting new development is the use of FlFFF as one of the separation techniques in a two-dimensional liquid-phase separation system. The group of Moon [1416] worked on the coupling of isoelectric focusing (IEF) and FIFFF for proteomics applications. In the first study, IEF separations were first performed in a polytetrafluoroethylene capillary; fractions were transferred to a HFFIFFF system with a switching valve. Since the second-dimension HFFlFFF separation was relatively slow, only a few fractions could be taken. In the later studies, a multilane AsFlFFF channel system was used. The separation of proteins on the basis of their isoelectric point was performed in an open thin segment in a channel that acted as the beginning part of six parallel AsFlFFF lanes. With this setup the relatively slow AsFlFFF separations of the fractions could be done simultaneously. The IEF-AsFIFFF multilane channel system developed was tested on standard proteins and a human urinary proteome sample. The entire proteome separation was achieved in less than 30 min using two ampholyte solutions with different $\mathrm{pH}$ ranges.

Yohannes et al. [17] used AsFlFFF as the first dimension in a comprehensive two-dimensional system. With a tenport interface valve, AsFlFFF fractions were transferred to a gradient reversed-phase LC system. Since the gradient time of the LC system was short (5 min including regeneration), a fair number of fractions could be taken during the AsFlFFF separation time of $120 \mathrm{~min}$. The twodimensional system was applied to study egg white denaturation (see Fig. 2).

\section{Biomacromolecules}

Starches and celluloses

Modig et al. [18] and Nilsson et al. [19] used an AsFlFFF instrument with MALS and RI detectors to study the effect of high-pressure homogenization on the molecular size and conformation of hydrophobically modified starches. Different starches, from potato and barley, had been modified with octenyl succinate anhydride (OSA). These OSAmodified starches are used in various food applications for the stabilization of dispersions. High-pressure homogenization is a commonly applied method to prepare emulsions. From the changes in retention in the AsFIFFF separation and from the MALS signals it was very clear that the

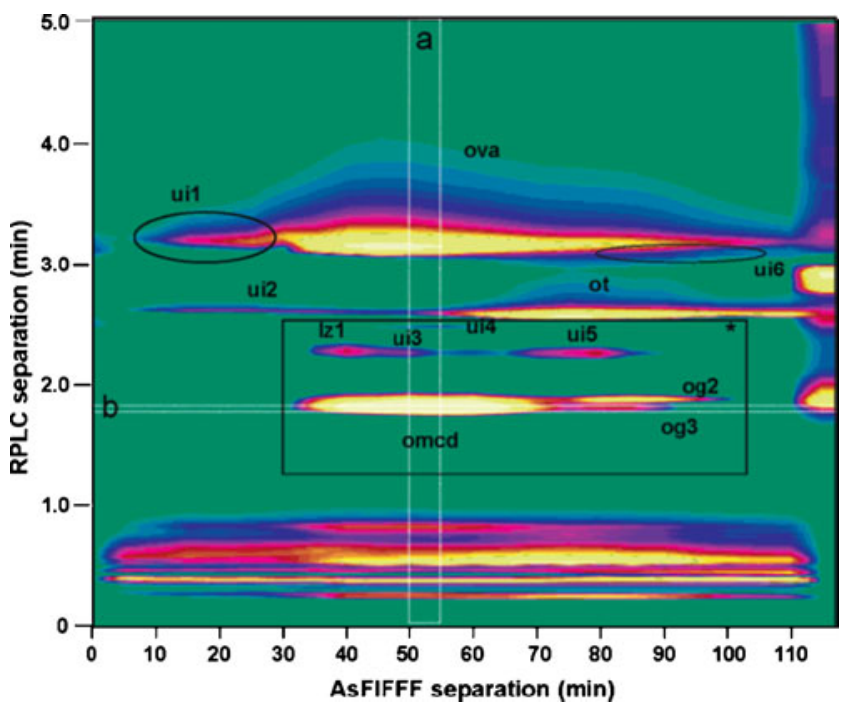

Fig. 2 AsFlFFF-high-performance liquid chromatography twodimensional separation of an egg white sample. $R P L C$ reversed-phase liquid chromatography (Reproduced from [17], with permission)

homogenization process caused a strong reduction in molecular size. For the original samples molecular masses from 23 to $86 \mathrm{MDa}$ were found. After the homogenization process the average values for the different samples ranged from 7 to $12 \mathrm{MDa}$. However, apart from the observed molecular breakdown (or the disruption of aggregates present in the original samples) other conformational changes were also observed. A comparison of the scattering radius (as obtained from the angular dependence of the MALS signal) with the molecular weight (as obtained from the ratio of the scattering and the RI signals) of the separated starch fractions showed that molecules of the modified starches become more compact by high-pressure homogenization. Before homogenization the density is of the order of $10 \mathrm{~kg} / \mathrm{m}^{3}$; after homogenization it increases to $20-100 \mathrm{~kg} / \mathrm{m}^{3}$. On the other hand, the ratio of the scattering radius to the hydrodynamic radius (as obtained from the retention time) decreases upon homogenization. It appears that homogenization makes the starch molecules more spatially distributed. The authors explained these apparently contradicting results with a model of the degradation process that they described as a simultaneous "crumpling" of the core and a "fraying" of the outer parts of the macromolecules. Similar conformational changes upon homogenization were found for (unmodified) waxy barley starches [20]. Later work by the same group, performed with AsFlFFF, showed that in emulsification processes the larger OSA-modified starch molecules are preferentially adsorbed on the cyclohexane/water interface [21].

Bowen et al. [22] used AsFlFFF with triple-angle light scattering and RI detection to study the degradation of waxy maize starches in extruded (solid) samples containing 
lipids. Samples were first dissolved in 95\% dimethyl sulfoxide/water, then precipitated by adding ethanol, and redissolved in water at $140{ }^{\circ} \mathrm{C}$ under pressure. An optimized cross-flow program was applied for the fractionation, with water as the carrier solution. The parameters of the extrusion process were shown to have a large effect on the molecular size of the starches in the products. The presence of (sunflower) oil in the sample apparently prevented part of the breakdown of the starch molecules during extrusion (see Fig. 3). A significant decrease of the average molecular weight of the amylopectins was found during storage only when the samples contained sunflower oil and copper ions or free fatty acids. The starch degradation was shown to be related to the lipid oxidation occurring at higher storage temperatures. Molecular weight determinations with AsFlFFF appeared to be difficult for these samples. First, the recoveries, for starches as well as for the pullulan standards used, were always below $70 \%$. Secondly, the molecular masses obtained by AsFlFFF were significantly higher (of the order of $80-150 \mathrm{MDa}$ ) those obtained by static light scattering (approximately $16 \mathrm{MDa}$ ). However, the determination of the molecular weight or size of starch molecules is notoriously difficult and ambiguous, also with other analysis techniques [23].

Krentz et al. [24] determined the molar mass distributions and the size (radius of gyration) of highly cationized starch derivatives with AsFlFFF-MALS. The starches had been modified with 2-hydroxy-3-trimethylammoniumpropyl groups. Such modified starches are used as flocculation agents in, e.g., wastewater treatment. The relation between the amylose-to-amylopectin ratio, degree of substitution, molar mass distribution, and flocculation efficiency was studied. Here, again, the molecular size determination was not straightforward. The elution patterns obtained varied with the flow rates employed. Under certain conditions an elution inversion (with the molecules with the largest radius of gyration being eluted first) was observed. The average molecular masses for samples of different origin were found to be between 36 and $69 \mathrm{MDa}$, and the radius of gyration was between 130 and $170 \mathrm{~nm}$.

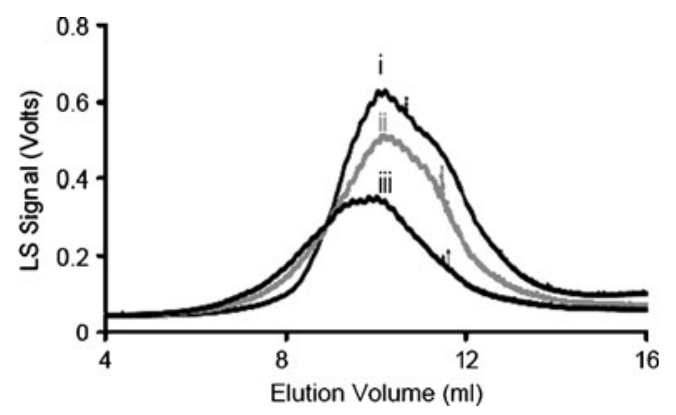

Fig. 3 Light scattering $(L S)$ signal in AsFlFFF of waxy maize starch samples: native(i); after extrusion with fresh sunflower oil (ii); after extrusion without oil (iii). (Reproduced from [22], with permission)
The structural characteristics and branching features of amylopectins were studied in detail by Rolland-Sabate et al. [25] with AsFlFFF-MALS. Amylose-free starches from different botanical sources were dissolved in dimethyl sulfoxide, dried, and redissolved in water by microwave heating under pressure. Water with sodium azide was used as the carrier solution, and the fractionation was performed with a linear cross-flow gradient. The elution recovery was between 82 and $100 \%$ for the different starches. Molecular masses were found in the range 100-300 MDa. From the relation between the radius of gyration (obtained from the MALS data) and the molecular weight (obtained from the ratio of the scattering and the RI signals) over the size distributions, conclusions could be drawn on the density and branching of the different samples. Waxy maize starch was found to have highest degree of branching. To get meaningful results in these studies, the AsFlFFF conditions had to be carefully optimized. Under the conditions described, good recoveries and limited overloading effects were observed. It was noted, however, that with a new membrane from a different supplier, these results could not be reproduced.

Most studies on the characterization of starches deal with the polysaccharides after solubilization. However, Contado and Wahlund [26] have shown that AsFlFFF can also be applied to size the original granules of which starches are composed. These granules are spherical or disk-shaped and have diameters between 1 and $40 \mu \mathrm{m}$. For such large particles AsFIFFF works in the steric or hyperlayer mode, with the largest particles being eluted first. The fractograms obtained in this study, for the parent samples and for different fractions obtained by sedimentation procedures and SPLITT fractionation, show a bimodal distribution of the granule size of wheat and barley starches.

The separation capability of AsFIFFF with programmed cross flow was tested for water-soluble hydroxypropyl cellulose covering the molar mass range from 5.8 to $1,600 \mathrm{kDa}$ [27]. It was possible to separate the entire range of the molar mass distribution with both linear and exponential decay cross-flow programs. However, the separation with an exponential decay program was more favorable when selectivity in the high molar mass range was needed. Moreover, the exponential decay program allowed the elution of the (unknown) largest component present in the sample as the cross flow never reaches zero.

Functional polysaccharides

Linear polysaccharides, obtained from different biological sources, are used as thickening, emulsifying, or stabilizing agents in various applications and in pharmaceutical products. Establishing the molecular size (distribution) of these polysaccharides is important in product control. 
Lee et al. [28] studied the AsFlFFF characterization of sodium hyaluronate. The effects of different cross-flow decay patterns, the mobile phase ionic strength, and the injection volume and concentration were studied. It was concluded that with different flow programs, which may be linear, exponential or mixed, a successful fractionation of biopolymers with a broad molecular weight distribution can be obtained. The average molecular mass of the material studied was around $1 \mathrm{MDa}$. However, the quantitative results strongly depended on the experimental conditions. The salt concentration of the carrier solution appeared to have a large effect on the retention of the (charged) hyaluronate molecules.

A series of papers have been published in which AsFIFFF-MALS was applied to study the degradation of ultrahigh molecular weight hyaluronate under the influence of thermal treatment [29,30], $\gamma$ irradiation [31], and ultrasonic, enzymatic or alkaline treatment [32]. Degradation products with molecular masses around $50 \mathrm{kDa}$ could be detected next to the original compounds with molecular masses up to $100 \mathrm{MDa}$. Figure 4 shows as an example the change of the molecular weight distribution of a hyaluronate sample caused by ultrasonic degradation. Electron irradiation (a method utilized to sterilize raw materials) of scleroglucan, a branched polysaccharide, was shown by Augsten and Mader [33] to not alter the chemical structure. However, it caused scission of the long chains, which leads to decrease in the molecular size of the parent scleroglucan samples. The authors used gel permeation chromatography and AsFlFFF for the size characterization. AsFlFFF was found to be better suitable for the broad distributions of scleroglucan samples.

Chitosan is a natural cationic polysaccharide that finds increasing use in pharmaceutical applications, e.g., as an

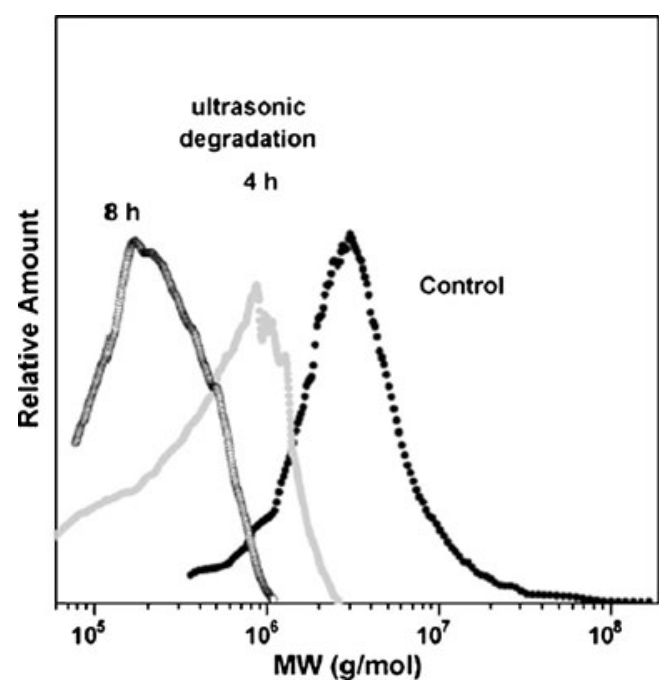

Fig. 4 Change of the molecular weight $(M W)$ distribution of hyaluronate by ultrasonic degradation. (Reproduced from [32], with permission) excipient or drug carrier. AsFlFFF-MALS-RI detection was applied to characterize various commercial chitosan types and batches of pharmaceutical interest [34, 35]. A monomodal logarithmic Gaussian type of molar mass distribution was observed for most of the chitosan types, with an average between 40 and $100 \mathrm{kDa}$, with very high batch-to-batch variations. Advantages of AsFlFFF mentioned in this study were the broad mass range that could be covered, and the fact that samples could be analyzed without purification. Online AsFlFFF-UV/vis-MALSDLS investigations of DNA/chitosan complexes made it possible to obtain in a single measurement the size and size distribution of the complexes together with the content of unbound polycation (chitosan). To facilitate the UV/vis detection, the chitosans were labeled with rhodamine $\mathrm{B}$. AsFlFFF analysis revealed that $73 \%$ rhodamine-labeled chitosan remained free in solution during the formation of complexes, and that the size of the DNA/chitosan complexes ranged from 20 to $160 \mathrm{~nm}$ [36].

A comprehensive study on the conformational changes of $\alpha$-carrageenan occurring in the presence of salts was performed by Bourgoin et al. [37] using AsFlFFF-MALS. A pronounced increase in the molecular weight of $\alpha$ carrageenan was found in the presence of $0.1 \mathrm{M} \mathrm{NaI}$ as compared with $0.1 \mathrm{M} \mathrm{NaCl}$. On the other hand, the radius of gyration was not increased. These salt concentrations apparently induced stronger molecular interactions and consequently lead to compact structures of the polysaccharide (coaxial helices).

The unique characteristics of ampholytic and amphiphilic pullulan derivatives in solution give these compounds useful industrial applications [38]. For the physiochemical characterization of these compounds AsFlFFF-MALS-QELS was used [39]. The authors were able to detect some degraded products and high-aggregation compounds produced during the modification of the pullulans.

Storz et al. [40] used AsFIFFF in a study on the physicochemical features of ultra-high-viscosity alginates. Alginates are linear anionic polysaccharides. AsFlFFF was used as a confirmatory technique for size-exclusion chromatography (SEC), especially for the alginates with the highest molar masses. A good agreement between SEC and AsFlFFF results was found.

Proteins and protein aggregation

AsFIFFF combined with MALS is stated to be a robust and reliable means for quantitative measurement of protein refolding in biotechnology [41]. AsFlFFF could discriminate between the yields of different refolding protocols, whereas high-performance LC could not. AsFlFFF-MALS was also used to determine the size distributions of inclusion bodies of green fluorescent proteins prepared 
under different culture conditions [42]. The typical size of the inclusion bodies (the non-refolded fraction of the recombinant protein) was found to be about $700 \mathrm{~nm}$. Heat-induced structural changes of monomers and aggregates of immunoglobulin $\mathrm{G}(\mathrm{IgG})$ were monitored in detail with AsFlFFF and online fluorescent dye detection [43]. In this study, a fluorescent dye was added to the carrier solution or the sample. High-performance SEC appeared to perform better for the separation of monomers and dimers, but AsFIFFF gave a higher recovery for larger aggregates. The increased fluorescence intensity observed after heating of $\operatorname{IgG}$ was attributed to aggregation of IgG as well as to structural changes. IgG aggregation was also studied by Demeule et al. [44]. In an acetic acid solution fairly stable aggregates were found, whereas the aggregates formed in phosphate buffer were more labile. The aggregates were easily disrupted during fractionation. AsFlFFF-MALS was used to study the aggregation of calsequestrin, a protein that plays a role in calcium regulation in the sarcoplasmic reticulum [45]. The experimental results supported the theory that calcium binding proteins aggregate through dimer interaction.

In our laboratory we have used AsFlFFF to study the heat-induced aggregation of $\beta$-lactoglobulin, a milk protein [11]. A time-delayed exponential cross-flow program was found to be optimal for the separation of protein monomers, oligomers, and large aggregates in one run.

Prion protein particles (PrPs) are known to be infectious and to lead to neurodegenerative diseases. Silveira et al. $[46,47]$ applied AsFlFFF-MALS to study the relationship between the size and the infectivity of protease-resistant $\operatorname{PrPs}\left(\mathrm{PrP}^{\mathrm{res}}\right)$. Quantitative light scattering of fractionated $\mathrm{PrP}^{\mathrm{res}}$ revealed that their size ranged between 10 and $250 \mathrm{~nm}$. The infectivity of $\operatorname{PrP}^{\text {res }}$ was highest for particles of $17-27 \mathrm{~nm}$, whereas the activity was substantially lower for large fibrils and virtually absent for oligomers of five or fewer PrP molecules.

Self-assembled aggregates of $A \beta$ proteins and peptides are crucial in the pathogenesis of Alzheimer's disease. The time-dependent amyloid $A \beta_{1-42}$ aggregation pattern was studied with AsFlFFF-MALS by Rambaldi et al. [48]. The data obtained in terms of molar mass and size provided unique information on the dynamic aggregation process.

Kang et al. [49] used frit-inlet AsFlFFF for the fractionation of membrane proteins from cytoplasmic proteins of prostatic cancer cell lysates before their mass characterization by nano LC-ESI-MS-MS. The efficiency of AsFlFFF for the prefractionation membrane proteins was compared with that of a conventional ultracentrifugation method. It was found that application of AsFlFFF increased the yield of purified membrane proteins. The application of AsFlFFF as a purification method was also reported by $\mathrm{Li}$ et al. [50]. They used the method to clean up protein complexes adsorbed to polystyrene particles.
Bioparticles

\section{Lipoproteins}

AsFlFFF has been shown to be a very promising technique in profiling human serum lipoproteins and to study lipid transfer mechanisms. Setala et al. [51] used AsFlFFF to follow the transfer mechanisms of phospholipids and phospholipid transfer proteins between small unilamellar lipid vesicles (SUVs) and high-density lipoproteins (HDLs). Radiolabeled SUVs, proteins, and HDLs were allowed to exchange lipids, and after the reaction the SUVs and HDLs were separated by AsFlFFF. The AsFlFFF system was also used to estimate the size of HDLs and SUVs.

Yohannes et al. [5] showed the separation of different lipoprotein types with a miniaturized AsFlFFF system. The results showed a shorter analysis time, a smaller sample requirement, and low consumption of mobile phase with the miniaturized system. The optimized AsFlFFF system was used to study low-density lipoprotein (LDL) aggregation and fusion after enzyme treatment.

Lipoproteins and associated cholesterol and triglyceride abnormalities are strongly connected to coronary artery diseases. Therefore, a correct size and shape characterization of lipoprotein subclasses in the serum of patients, prior to cardiovascular treatment, may improve diagnosis and remedial methodology.

Rambaldi et al. [52] showed the feasibility of AsFlFFFMALS and HFFIFFF-MALS for size and shape characterization of lipoproteins from a whole serum sample. The calculated sizes of HDL and LDL molecules were in agreement with those of other methods.

Recently, the determination of cholesterol and triglyceride patterns, associated with lipoprotein subclasses, was shown by AsFlFFF with online enzymatic detection [53, 54]. The effluent of the AsFlFFF system, which separated the lipoprotein species on the basis of size, was merged with enzymatic reagents specific for cholesterol or triglycerides. The reaction products could be monitored with UV/vis detectors, and quantitative concentration patterns were obtained (see Fig. 5). The method developed opens up an interesting perspective for fast lipoprotein profiling. Quantitative results for cholesterol and triglycerides in the serum of healthy donors and patients were in good agreement with the results of methods that are conventionally used in clinical laboratories.

\section{Viruslike particles}

Recent developments in the field of biotechnology have shown the potential use of viruslike particles (VLPs) in the prevention of virus-induced diseases, in vaccination, gene therapy, and drug delivery. VLPs are biomolecular nano- 


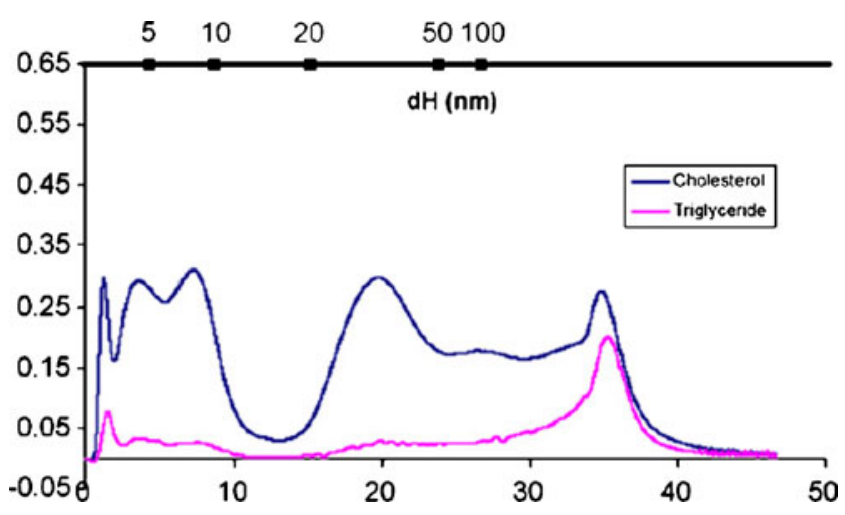

Fig. 5 Cholesterol and triglyceride profiles of a human serum sample as obtained by AsFlFFF with enzymatic detection. (Reproduced from [53], with permission)

particles formed by self-assembly of viral proteins. For the most reliable and safest use of these particles in commercial pharmaceutical products, advanced analytical tools are required for their quantification and for stability, size, and aggregation studies. The soft and gentle nature of the separation principle of AsFlFFF, by which the structure and conformation of analytes is preserved, makes it a very valuable technique for the precise characterization of VLPs [55]. It has been shown that with carefully selected crossflow programs, focusing times, and membrane materials, samples of VLPs can be separated into fragments, monomers, dimers, oligomers, and aggregates of VLPs (see Fig. 6). Interaction between VLPs and between VLPs and the membrane used in AsFlFFF may promote aggregation. However, Chuan et al. [56] have shown that such interactions can be minimized by optimizing the operating conditions. In the same study it was shown that AsFlFFF in combination with MALS provides more accurate size distribution information for heterogeneous samples of VLPs than transmission electron microscopy (TEM) or DLS. From a study by Pease et al. [57] on VLPs from the nonenveloped

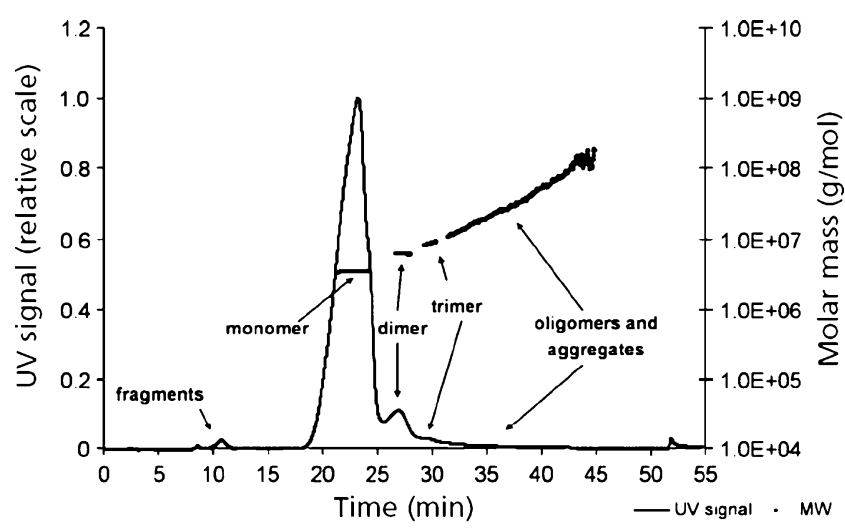

Fig. 6 AsFlFFF-multiangle light scattering characterization of viruslike particles. (Reproduced from [55], with permission) virus family Polyomaviridae it was concluded that variations in the size of VLPs, caused by subtle changes in the production processes, can be detected with greater speed and precision with AsFIFFF-MALS than with TEM. AsFlFFF-based analytical characterization has become indispensable for complete characterization of VLPs, as reported by Citkowicz et al. [58]. From a single analysis of DNA-VLP gene delivery vehicles by AsFlFFF, combined with diode array-MALS-RI-fluorescence detection, a complete picture could be obtained: the molar mass, the hydrodynamic and gyration radii, the composition and the purity of the final drug product. Lipin et al. [59] used AsFIFFF-MALS and DLS to determine the quaternary (aggregate) size distribution of glutathione $S$-transferase purified viral protein. Soluble VLP aggregates were shown to range from one to more than 50 pentamer architectures. The authors also successfully used AsFlFFF to measure the relative quantities of adsorption of differently sized VLP aggregates on the resin during purification by affinity chromatography [60]. An AsFlFFF-MALS method was also used by Wei et al. [61] for the determination of the size distribution and the total particle count of influenza virions during vaccine preparation processes. The pros and cons of AsFIFFF were compared with those of alternative analysis methods.

\section{Lipid vesicles}

Liposomes or phospholipid vesicles can be used as drug carriers in the bloodstream. The particle size and the particle size distribution are the key factors in liposomebased drug delivery systems that determine the encapsulation efficacy, colloidal stability, bioavailability, and targeting ability. Hupfeld et al. [62] showed an interdependence of fractionation parameters in size distribution studies of phosphatidylcholine liposomes with AsFlFFF in combination with MALS, RI, and UV/vis detection. In this study it was concluded that the retention behavior of liposomes was governed by the flow conditions, as expected, but also by the ionic strength of the carrier solution and by the sample load. Moreover, sample loss due to adsorption on the regenerated cellulose membrane had to be minimized by membrane presaturation with a sample load of at least $2 \mu \mathrm{g}$ [63]. It was also shown that online quantification of phosphatidylcholine liposomes could be improved by using colored markers such as Sudan red by and UV/vis detection, with higher sensitivity as compared with RI detection. AsFlFFF-MALS studies provided insight into size changes of liposomes under the influence of the osmotic pressure, by determination of the effect of the ionic strength of the carrier solution on the fractionation [64].

Liposomes are also applied in blood substitutes. Li et al. [65] applied AsFlFFF-MALS-RI detection to determine 
the shape, size, and encapsulation efficiency of liposomeencapsulated hemoglobin (LEHb) dispersions. The size distribution of different LEHb types was determined by AsFIFFF-MALS. From the MALS data it was concluded that empty liposomes and "plain" LEHb are spherical, whereas actin-modified LEHb has a thin-disk shape. Arifin and Palmer [66] used experimental AsFlFFF data to validate a theoretical model on LEHb size distributions to obtain more insight into LEHb stabilization. Good agreement was found for LEHb molecules extruded through membranes with a pore diameter of $100 \mathrm{~nm}$ or larger, but not with a smaller pore size. Yohannes et al. [67] studied the stability of zwitterionic phosphatidylcholine vesicles by measuring size changes of liposomes in the presence of different chemical modifiers with AsFIFFF. No significant change in diameter was observed after 5 months of storage at $4{ }^{\circ} \mathrm{C}$. After longer storage times, destabilized aggregates were found. Recently, a method to measure the efficiency of entrapment of dyes by liposomes, and to characterize an ensemble of liposomes at a very low concentration (zero to ten molecules), was described [68]. The method was based on fluorescence fluctuation analysis and on AsFlFFFMALS. It is claimed that it can be used for accurate characterization during the development of liposome standard reference materials [66]. AsFlFFF with MALS and online DLS was used to characterize vesicles of controlled size produced in a microfluidic channel [69]. It was found that the size distribution of the liposomes was tunable over a mean diameter from 50 to $150 \mathrm{~nm}$.

The nanometer-scale sized-based separation of exosomes obtained from human neural stem cells by miniaturized fritinlet AsFIFFF was reported by Kang et al. [70]. Exosomes are small membrane vesicles with a diameter in the range 30-100 nm. AsFlFFF coupled with MS required less starting material for analysis as compared with gel-based separation, digestion, and an MS-MS method.

\section{Drug delivery particles}

The determination of the physicochemical properties, and especially the size distribution, of biodegradable compounds in drug delivery systems is extremely important because different organs are targeted by differently sized particles. AsFlFFF with various detection modes leads to fast and low-cost routine size analysis during synthesis and purification of drug-carrying compounds. Contado et al. [71] compared AsFlFFF and sedimentation field-flow fractionation for the size characterization of polylactic acid nanospheres that were used to encapsulate certain neuroprotective prodrugs. The use to these two complementary techniques led to finding the most suitable suspending medium for polylactic acid analysis. The fractograms obtained by AsFlFFF could be easily transformed into a particle size distribution. The size information obtained from AsFIFFF appeared to be very accurate, especially for nanoparticles smaller than 250-300 $\mathrm{nm}$. For the size characterization of poly(D,L-lactide-co-glycolide) nanosuspensions, Augsten et al. [72] used small-angle X-ray scattering, photon correlation spectroscopy, and AsFlFFFMALS. AsFIFFF allowed easy detection of the maximum particle size. High-quality size distributions could be obtained with MALS owing to the AsFlFFF separation applied prior to the size characterization. Good correlation with photon correlation spectroscopy data was obtained. The potential of AsFIFFF with RI detection was explored in the quantification of the PEGylation (PEG binding) process of gelatin nanoparticle drug carrier systems [73]. AsFlFFF was used to separate the PEG in the reaction mixture from the gelatin nanoparticles. The PEGylation could be quantified from the RI detector signal for the unreacted PEG peak. The maximum amount of PEG that could bind to nanoparticles was determined (approximately $35 \% \mathrm{w} / \mathrm{w}$ ).

An accurate size distribution of drug-loaded core/shell nanoparticles, composed of a lipid core and pluronic shell, using AsFIFFF was also reported [74]. AsFIFFF enabled the separation of the drug-loaded particles, with a size from 100 to $600 \mathrm{~nm}$, from small coreless polymeric micelles. Polyamidoamine (PAMAM) dendrimers that are applied in drug delivery systems have $\mathrm{pH}$-dependent physicochemical properties. AsFlFFF provides a generation-based separation of these highly charged PAMAM dendrimers under acidic, neutral, or even basic conditions (see Fig. 7), as reported by Lee et al. [75]. AsFlFFF size analysis under neutral conditions made it possible to study the interaction between bovine serum albumin and PAMAM dendrimers. It was shown that the apparent bovine serum albumin size increased with increasing concentration of dendrimers, as a result of the complex formation with the dendrimers.

Hydrolytically degradable nanogels, formed by copolymerization of $N$-isopropylmethacrylamide (NIPMAm) and

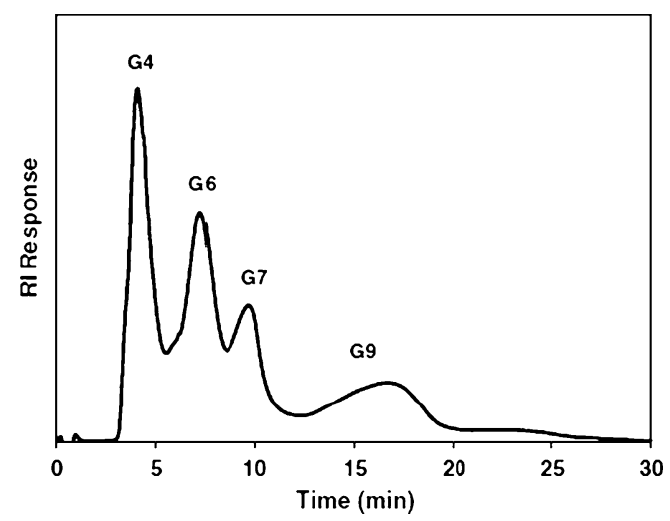

Fig. 7 AsFlFFF separation of polyamidoamine dendrimer generations. $R I$ refractive index. (Reproduced from [75], with permission) 
$\mathrm{N}, \mathrm{O}$-dimethacryloylhydroxylamine (DMHA), form a unique class of drug delivery vehicle. AsFIFFF-MALS was used to characterize the temperature- and $\mathrm{pH}$ dependent erosion of NIPMAm-DMHA nanogels in various media [76]. AsFlFFF was used to separate the particles from degradation products. Erosion-induced swelling could be monitored from the increase in the radius of gyration (by MALS), whereas the loss of mass from the particles was evident from the decrease in scattering intensity.

\section{Natural colloids}

Many applications of AsFlFFF have been reported for the fractionation of natural colloids in aquatic media. Environmental colloids play an important role in the mobility and bioavailability of pollutants and trace elements. Natural colloids can be composed of organic (humic and fulvic compounds) and inorganic (clays, iron oxyhydroxide) components. Dubascoux et al. [77] have investigated AsFlFFF parameters to get maximum sample recovery and satisfactory separation of (mostly inorganic) soil leachates. The ionic strength of the carrier solution was found to be a key parameter that can influence sample recovery during fractionation. AsFlFFF-MALS coupling was used to assess the colloidal dispersions and sedimentation behavior of colloidal soil extracts in the presence of carbonates [78, 79]. AsFIFFF and offline atomic force microscopy have been used for quantifying fine (less than $5 \mathrm{~nm}$ ) aquatic colloid properties [80]. The relative molar mass distribution of the optical properties of chromophoric colloidal organic matter in oceanic water was studied with AsFlFFF-UV-fluorescence detection [81]. The relative molar mass distributions were used to estimate the number-average and weight-average relative masses and polydispersity indices. The effect of the origin of the seawater and the salinity on the relative molar masses of the chromophoric and fluorescent components was studied. Reszat and Hendry [82] have shown that online coupling of a AsFlFFF system with a dissolved organic carbon (DOC) detector provides better insight into the molecular weight of DOC in natural groundwater and surface water samples. The DOC results gave higher values for the molecular weight than a UV detector. An explanation for this discrepancy was that the UV detector is not sensitive for aliphatic compounds.

The colloidal matter in water reservoirs is recognized as a trace metal carrier. AsFlFFF coupled with inductively coupled plasma (ICP)-MS has made it possible to study the multielement composition and its size dependency of natural colloids of diverse origins (soil leachate, seep water, groundwater, sewage, river water and seawater [83-88]). An example of the application of AsFlFFF-ICP-MS is shown in Fig. 8. AsFIFFF with ICP-MS, AsFIFFF with TEM, and AsFlFFF with X-ray spectroscopy were used in series to investigate the relationship between physical properties (size) and chemical properties (composition, surface chemical composition, and trace element association) of aquatic colloids. $\mathrm{Al}, \mathrm{Fe}$, and $\mathrm{Mn}$ were found to be the main components of colloids in the size range 0.01$0.45 \mathrm{~nm}$ [89]. Stolpe et al. [90] utilized online AsFlFFFhigh resolution ICP-MS for the measurement of the colloidal distribution of elements. The approach allowed the identification of 45 elements and their simultaneous quantification in a single run of (preconcentrated) natural freshwater samples. The estuarine behavior of $0.5-50-\mathrm{nm}$ colloids was followed upon mixing of natural freshwater with synthetic seawater [91]. Two types of nanoscaled colloid carriers could be discerned, i.e., fluorescent dissolved organic matter (FDOM) and colored dissolved organic matter (CDOM). It was observed that the small $(0.5-3-\mathrm{nm})$ and Fe-rich FDOM colloids aggregated after mixing with seawater to a size range above $50 \mathrm{~nm}$, whereas CDOM colloids were resistant to high salt concentrations. In another study at least three classes of colloids were identified and characterized in different water samples: 0.5-4-nm CDOM, 3-8-nm proteinlike colloids, and 5-40-nm Fe-rich particles [92]. AsFlFFF combined with a radiotracer method made it possible to follow the introduction of iron-containing colloids into coastal seawater from peatland-draining rivers [93]. Excitation-emission matrix spectroscopy of marine CDOM after AsFlFFF size fractionation made it possible to

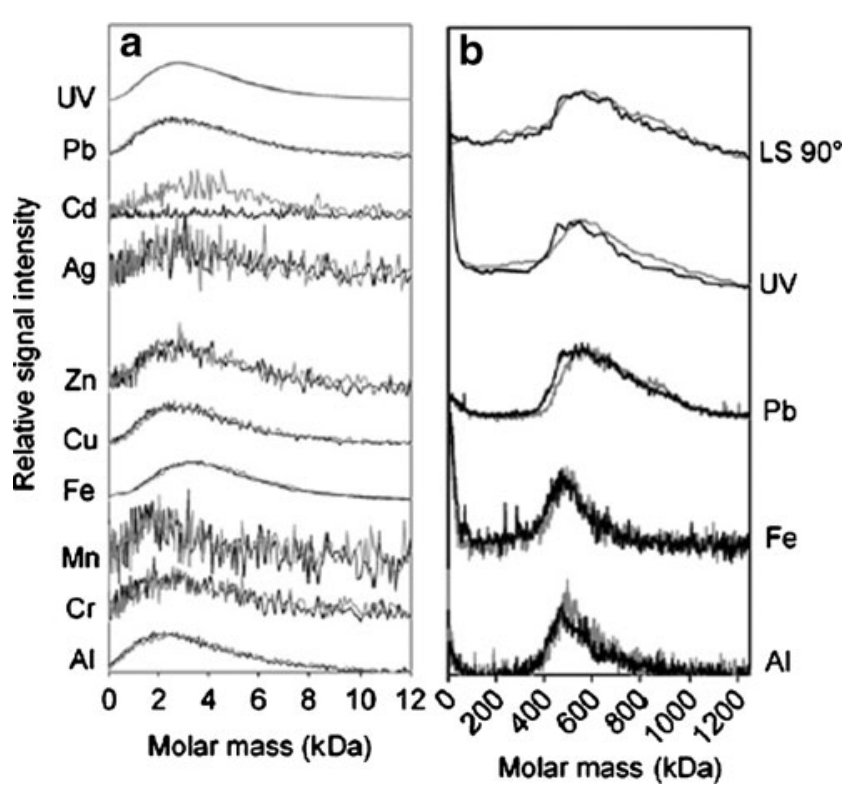

Fig. 8 Element distribution over colloidal organic matter from the low (a) and high (b) molecular mass colloid fractions of the effluent of a wastewater treatment plant, as obtained by AsFlFFF-inductively coupled plasma-mass spectrometry. (Reproduced from [88], with permission) 
distinguish small proteinlike and large humiclike fluorescent materials in natural organic matter [94]. The monitoring of uranium complexation with DOC in groundwater is extremely important in nuclear waste management. AsFIFFF-UV-ICP-MS appeared to be a useful technique for determining in situ U-DOC association constants, even in the very small sample volumes $(20-50 \mu \mathrm{L})$ [95].

\section{Conclusions}

The literature study conducted has shown that today FlFFF is applied on a routine basis in a variety of application fields: in industrial and pharmaceutical analysis, in biomedical studies, in food analysis, and in environmental applications. As the main virtues of the technique, compared with alternative separation methods, the "soft" character of the separation process (which makes it possible to fractionate fragile macromolecules and particles) and the wide size or molecular mass range that can be handled are mentioned. When used in combination with MALS or DLS detection, valuable information on the size and shape of macromolecules and particles can be obtained. Coupling with MS or ICPMS is relatively easy. Such coupled systems have been shown to provide valuable information for compound or element identification, and on the relation between the size and composition of macromolecules and particles.

Acknowledgements R.N.Q. acknowledges the Higher Education Commission, Pakistan, and NUFFIC, the Netherlands, for a research scholarship.

Open Access This article is distributed under the terms of the Creative Commons Attribution Noncommercial License which permits any noncommercial use, distribution, and reproduction in any medium, provided the original author(s) and source are credited.

\section{References}

1. Giddings JC, Yang FJF, Myers MN (1976) Science 193 (4259):1244-1245

2. Roda B, Zattoni A, Reschiglian P, Moon MH, Mirasoli M, Michelini E, Roda A (2009) Anal Chim Acta 635(2):132-143

3. Reschiglian P, Zattoni A, Roda B, Michelini E, Roda A (2005) Trends Biotechnol 23(9):475-483

4. Qureshi RN, Kok WT (2010) LC GC Eur 23(1):18-25

5. Yohannes G, Sneck M, Varjo SJ, Jussila M, Wiedmer SK, Kovanen PT, Oorni K, Riekkola ML (2006) Anal Biochem 354(2):255-265

6. Reschiglian P, Zattoni A, Roda B, Cinque L, Parisi D, Roda A, Dal Piaz F, Moon MH, Min BR (2005) Anal Chem 77(1):47-56

7. Zattoni A, Rambaldi DC, Roda A, Parisi D, Roda A, Moon MH, Reschiglian P (2008) J Chromatogr A 1183(1-2):135-142

8. Kang D, Moon MH (2005) Anal Chem 77(13):4207-4212

9. Park Y, Paeng KJ, Kang D, Moon MH (2005) J Sep Sci 28 (16):2043-2049
10. Kim KH, Kang D, Koo HM, Moon MH (2008) J Proteomics 71 (1):123-131

11. Zhu RH, Frankema W, Huo YL, Kok WT (2005) Anal Chem 77 (14):4581-4586

12. Le Cerf D, Simon S, Argillier JF, Picton L (2007) Anal Chim Acta 604(1):2-8

13. Isaacson CW, Bouchard D (2010) J Chromatogr A 1217(9):15061512

14. Kang DJ, Moon MH (2006) Anal Chem 78(16):5789-5798

15. Kim KH, Moon MH (2009) J Proteome Res 8(9):4272-4278

16. Kim KH, Moon MH (2009) Anal Chem 81(4):1715-1721

17. Yohannes G, Wiedmer SK, Hiidenhovi J, Hietanen A, Hyotylainen T (2007) Anal Chem 79(8):3091-3098

18. Modig G, Nilsson L, Bergenstahl B, Wahlund KG (2006) Food Hydrocolloids 20(7):1087-1095

19. Nilsson L, Leeman M, Wahlund KG, Bergenstahl B (2006) Biomacromolecules 7(9):2671-2679

20. Rojas CC, Wahlund KG, Bergenstahl B, Nilsson L (2008) Biomacromolecules 9(6):1684-1690

21. Nilsson L, Leeman M, Wahlund KG, Bergenstahl B (2007) Langmuir 23(5):2346-2351

22. Bowen SE, Gray DA, Giraud C, Majzoobi M, Testa CEM, Perez LAB, Hill SE (2006) J Cereal Sci 43(3):275-283

23. Gidley MJ, Hanashiro I, Hani NM, Hill SE, Huber A, Jane JL, Liu Q, Morris GA, Rolland-Sabate A, Striegel AM, Gilbert RG (2010) Carbohydr Polym 79(2):255-261

24. Krentz DO, Lohmann C, Schwarz S, Bratskaya S, Liebert T, Laube J, Heinze T, Kulicke WM (2006) Starch Starke 58(34):161-169

25. Rolland-Sabate A, Colonna P, Mendez-Montealvo MG, Planchot V (2007) Biomacromolecules 8(8):2520-2532

26. Contado C, Wahlund KG (2006) Starch Starke 58(3-4):140-154

27. Leeman M, Wahlund KG, Wittgren B (2006) J Chromatogr A 1134(1-2):236-245

28. Lee H, Kim H, Moon MH (2005) J Chromatogr A 1089(12):203-210

29. Lee H, Cho IH, Moon MH (2006) J Chromatogr A 1131(12):185-191

30. Kwon JH, Hwang E, Cho IH, Moon MH (2009) Anal Bioanal Chem 395(2):519-525

31. Shin DY, Hwang E, Cho IH, Moon MH (2007) J Chromatogr A 1160(1-2):270-275

32. Moon MH, Shin DY, Lee N, Hwang E, Cho IH (2008) J Chromatogr B Anal Technol Biomed Life Sci 864(1-2):15-21

33. Augsten C, Knolle W, Mader K (2008) Carbohydr Polym 72 (4):707-718

34. Mao S, Augsten C, Mader K, Kissel T (2007) J Pharm Biomed Anal 45(5):736-741

35. Augsten C, Mader K (2008) Int J Pharm 351(1-2):23-30

36. Ma PL, Buschmann MD, Winnik FM (2010) Biomacromolecules 11(3):549-554

37. Bourgoin A, Zablackis E, Poli JB (2008) Food Hydrocolloids 22 (8):1607-1611

38. Souguir Z, Roudesli S, Picton L, Le Cerf D, About-Jaudet E (2007) Eur Polym J 43(12):4940-4950

39. Souguir Z, Roudesli S, About-Jaudet E, Le Cerf D, Picton L (2007) J Colloid Interface Sci 313(1):108-116

40. Storz H, Muller KJ, Ehrhart F, Gomez I, Shirley SG, Gessner P, Zimmermann G, Weyand E, Sukhorukov VL, Forst T, Weber MM, Zimmermann H, Kulicke WM, Zimmermann U (2009) Carbohydr Res 344(8):985-995

41. Johann C, Ramage P, Hemmig R (2005) LC GC Eur 18(10):532538

42. Luo J, Leeman M, Ballagi A, Elfwing A, Su ZG, Janson JC, Wahlund KG (2006) J Chromatogr A 1120(1-2):158-164 
43. Hawe A, Friess W, Sutter M, Jiskoot W (2008) Anal Biochem 378 (2):115-122

44. Demeule B, Lawrence MJ, Drake AF, Gurny R, Arvinte T (2007) Biochim Biophys Acta Proteins Proteomics 1774(1):146-153

45. Shadle SE, Rostock R, Bonfrisco L, Schimpf ME (2007) J Liq Chromatogr Relat Technol 30(9-12):1513-1523

46. Silveira JR, Hughson AG, Caughey B (2006) Meth Enzymol 412:21-33

47. Silveira JR, Raymond GJ, Hughson AG, Race RE, Sim VL, Hayes SF, Caughey B (2005) Nature 437(7056):257-261

48. Rambaldi DC, Zattoni A, Reschiglian P, Colombo R, De Lorenzi E (2009) Anal Bioanal Chem 394(8):2145-2149

49. Kang D, Yoo JS, Kim MO, Moon MH (2009) J Proteome Res 8 (2):982-991

50. Li JS, Ge JP, Yin YD, Zhong WW (2008) Anal Chem 80 (18):7068-7074

51. Setala NL, Holopainen JM, Metso J, Wiedmer SK, Yohannes G, Kinnunen PKJ, Ehnholm C, Jauhiainen M (2007) Biochemistry 46(5):1312-1319 (Mosc)

52. Rambaldi DC, Zattoni A, Casolari S, Reschiglian P, Roessner D, Johann C (2007) Clin Chem 53(11):2026-2029

53. Qureshi RN, Kok WT, Schoenmakers PJ (2009) Anal Chim Acta 654(1):85-91

54. Rambaldi DC, Reschiglian P, Zattoni A, Johann C (2009) Anal Chim Acta 654(1):64-70

55. Lang R, Vogt L, Zurcher A, Winter G (2009) LC GG North Am 27(9):844-885

56. Chuan YP, Fan YY, Lua L, Middelberg APJ (2008) Biotechnol Bioeng 99(6):1425-1433

57. Pease LF, Lipin DI, Tsai DH, Zachariah MR, Lua LHL, Tarlov MJ, Middelberg APJ (2009) Biotechnol Bioeng 102(3):845-855

58. Citkowicz A, Petry H, Harkins RN, Ast O, Cashion L, Goldmarm C, Bringmarm P, Plummer K, Larsen BR (2008) Anal Biochem 376(2): 163-172

59. Lipin DI, Lua LHL, Middelberg APJ (2008) J Chromatogr A 1190 (1-2):204-214

60. Lipin DI, Raj A, Lua LHL, Middelberg APJ (2009) J Chromatogr A 1216(30):5696-5708

61. Wei Z, McEvoy M, Razinkov V, Polozova A, Li E, Casas-Finet J, Tous GI, Balu P, Pan AA, Mehta H, Schenerman MA (2007) J Virol Meth 144(1-2):122-132

62. Hupfeld S, Ausbacher D, Brandl M (2009) J Sep Sci 32(9):1465-1470

63. Hupfeld S, Ausbacher D, Brandl M (2009) J Sep Sci 32 (20):3555-3561

64. Hupfeld S, Moen HH, Ausbacher D, Haas H, Brandl M (2010) Chem Phys Lipids 163(2):141-147

65. Li SL, Nickels J, Palmer AF (2005) Biomaterials 26(17):3759-3769

66. Arifin DR, Palmer AF (2005) Artif Cells Blood Substit Biotech 33 (2): $113-136$

67. Yohannes G, Pystynen KH, Riekkola ML, Wiedmer SK (2006) Anal Chim Acta 560(1-2):50-56

68. Reiner JE, Jahn A, Stavis SM, Culbertson MJ, Vreeland WN, Burden DL, Geist J, Gaitan M (2010) Anal Chem 82(1):180-188
69. Jahn A, Vreeland WN, DeVoe DL, Locascio LE, Gaitan M (2007) Langmuir 23(11):6289-6293

70. Kang DJ, Oh S, Ahn SM, Lee BH, Moon MH (2008) J Proteome Res 7(8):3475-3480

71. Contado C, Dalpiaz A, Leo E, Zborowski M, Williams PS (2007) J Chromatogr A 1157(1-2):321-335

72. Augsten C, Kiselev MA, Gehrke R, Hause G, Mader K (2008) J Pharm Biomed Anal 47(1):95-102

73. Zillies JC, Zwiorek K, Winter G, Coester C (2007) Anal Chem 79 (12):4574-4580

74. Kang DY, Kim MJ, Kim ST, Oh KS, Yuk SH, Lee SH (2008) Anal Bioanal Chem 390(8):2183-2188

75. Lee S, Kwen HD, Lee SK, Nehete SV (2010) Anal Bioanal Chem 396(4):1581-1588

76. Smith MH, South AB, Gaulding JC, Lyon LA (2010) Anal Chem 82(2):523-530

77. Dubascoux S, Von Der Kammer F, Le Hecho I, Gautier MP, Lespes G (2008) J Chromatogr A 1206(2):160-165

78. Kammer FVD, Baborowski M, Friese K (2005) Anal Chim Acta 552(1-2):166-174

79. Baalousha M, Kammer FVD, Motelica-Heino M, Hilal HS, Le Coustumer P (2006) J Chromatogr A 1104(1-2):272-281

80. Baalousha M, Lead JR (2007) Environ Sci Technol 41(4):11111117

81. Hassellov M (2005) Mar Chem 94(1-4):111-123

82. Reszat TN, Hendry MJ (2005) Anal Chem 77(13):4194-4200

83. Cizdziel JV, Guo CX, Steinberg SM, Yu ZB, Johannesson KH (2008) Environ Geochem Health 30(1):31-44

84. Celine CL, Lespes G, Dubascoux S, Aupiais J, Pointurier F, PotinGautier M (2009) J Chromatogr A 1216(52):9113-9119

85. Prestel H, Schott L, Niessner R, Panne U (2005) Water Res 39 (15):3541-3552

86. Bouby M, Geckeis H, Geyer FW (2008) Anal Bioanal Chem 392 (7-8):1447-1457

87. Bolea E, Gorriz MP, Bouby M, Laborda F, Castillo JR, Geckeis H (2006) J Chromatogr A 1129(2):236-246

88. Worms IAM, Szigeti ZAG, Dubascoux S, Lespes G, Traber J, Sigg L, Slaveykova VI (2010) Water Res 44(1):340-350

89. Baalousha M, Kammer FVD, Motelica-Heino M, Baborowski M, Hofmeister C, Le Coustumer P (2006) Environ Sci Technol 40 (7):2156-2162

90. Stolpe B, Hassellov M, Andersson K, Turner DR (2005) Anal Chim Acta 535(1-2):109-121

91. Stolpe B, Hassellov M (2007) Geochim Cosmochim Acta 71 (13):3292-3301

92. Stolpe B, Guo LD, Shiller AM, Hassellov M (2010) Mar Chem 118(3-4):119-128

93. Krachler R, Krachler RF, von der Kammer F, Suephandag A, Jirsa F, Ayromlou S, Hofmann T, Keppler BK (2010) Sci Total Environ 408(11):2402-2408

94. Boehme J, Wells M (2006) Mar Chem 101(1-2):95-103

95. Ranville JF, Hendry MJ, Reszat TN, Xie QL, Honeyman BD (2007) J Contam Hydrol 91(3-4):233-246 